\title{
A INFLUÊNCIA DE FILMES DA BARBIE SOBRE A EDUCAÇÃO SEXUAL DAS CRIANÇAS: NA BUSCA DA COMPREENSÃO DE PROFESSORAS SOBRE O TEMA
}

\author{
Raquel da Veiga PACHECO ${ }^{1}$ \\ Sonia Maria Martins de MELO $^{2}$
}

RESUMO: O presente artigo tem como objetivo refletir sobre a importância do desvelamento da compreensão de professoras sobre influências de filmes da boneca Barbie em processos de educação sexual de crianças. Entendemos que todos somos seres sexuados em relações educativas com o outro e com o mundo, relações estas que constroem conhecimento sempre sexuado. Uma vez que somos seres sexuados, portanto, tecemos relações sociais que são relações também de educação sexual, com ou sem intencionalidade. Essas relações educativas hoje são permeadas pelo uso intenso de várias ferramentas tecnológicas que se expressam em várias linguagens midiáticas que nunca são neutras em seus conteúdos. Dentre essas linguagens filmes infantis são frequentemente utilizados como apoio a processos educativos formais e não formais e influenciam o imaginário infantil. Dentre os filmes infantis, os da personagem Barbie são comumente utilizados por escolha das professoras como objetos pedagógicos dentro de muitas salas de aula como parte do cotidiano. O desvelar de como educadoras compreendem os reflexos desses filmes na educação sexual de seus discentes pode apontar novas possibilidades de uso crítico-pedagógico desses filmes.

PALAVRAS-CHAVE: Educação Sexual Emancipatória. Filmes da Barbie. Sexualidade. Mídias.

\section{Introdução}

Nos últimos anos cresceram em grande número as pesquisas sobre as diferenças exigidas nos processos de ensino-aprendizagem uma vez que as novas gerações, principalmente a nascida já no século XXI, tem sua educação acelerada pelo contato constante com a Sociedade do Conhecimento, uma vez que a criança já nasce inserida neste mundo repleto de várias linguagens midiáticas, o que vem causando, entre outras coisas, profundas transformações sociais e culturais, com um crescente aumento da velocidade das aprendizagens e descobertas. Neste texto pretende-se realizar algumas reflexões sobre esse fenômeno em interface com a temática da educação sexual, em

\footnotetext{
1 Mestre em Educação. UDESC - Universidade do Estado de Santa Catarina. Centro de Ciências Humanas e da Educação - Programa de Pós-Graduação em Educação. Florianópolis - SC - Brasil. 88035901 - raquelvpacheco@gmail.com.

2 Docente. UDESC - Universidade do Estado de Santa Catarina. Centro de Ciências Humanas e da Educação - Programa de Pós-Graduação em Educação. Florianópolis - SC - Brasil. 88035-901 soniademelo@gmail.com.
} 
especial na afirmação da necessidade de buscar a compreensão de professoras de educação infantil sobre as influências dos filmes da Barbie em processos de educação sexual de crianças. Esses filmes são vistos aqui como produtos que tem grandes possibilidades educomunicativas no que se refere a processos de educação sexual. Educomunicação entendida aqui como a propõe Soares (2015), que a define como um conjunto das ações destinadas a:

1 - integrar às práticas educativas o estudo sistemático dos sistemas de comunicação (cumprir o que solicita os PCNs no que diz respeito a observar como os meios de comunicação agem na sociedade e buscar formas de colaborar com nossos alunos para conviverem com eles de forma positiva, sem se deixarem manipular. Esta é a razão de tantas palestras sobre a comunicação e suas linguagens);

2 - criar e fortalecer ecossistemas comunicativos em espaços educativos (o que significa criar e rever as relações de comunicação na escola, entre direção, professores e alunos, bem como da escola para com a comunidade, criando sempre ambientes abertos e democráticos. Muitas das dinâmicas adotadas no Educom apontam para as contradições das formas autoritárias de comunicação);

3 - melhorar o coeficiente expressivo e comunicativo das ações educativas (Para tanto, incluímos o rádio como recurso privilegiado, tanto como facilitador no processo de aprendizagem, quanto como recurso de expressão para alunos, professores e membros da comunidade);

Como cada vez é maior a presença de diferentes linguagens midiáticas no cotidiano das escolas, Carvalho (2009, p.132) acrescenta ao papel do professor a necessidade de ser também um educomunicador:

[...] em um momento histórico em que as informações se processem de forma avassaladora, o educomunicador, professor que integra os diferentes meios em sua prática pedagógica, precisa buscar estratégias que estimulem esse jovem, criado na era das chamadas novas tecnologias, interagindo com o educando num processo em que os dois são sempre aprendentes.

Não há como negar que as Tecnologias de Informação e Comunicação (TIC) e nelas, os vários meios de comunicação e neles os filmes da Barbie, ainda hoje, após quase sessenta anos de existência dessa boneca icônica, exercem um grande poder educativo sobre as crianças, advindo da constante interação dessas com essa linguagem midiática que está presente há tanto tempo no nosso dia-a-dia. Linguagens midiáticas sempre estão vinculando ideias e concepções sobre sexualidade e estão educando 
sexualmente a todas as pessoas, mesmo que, muitas vezes, aparentemente, essas ideias e concepções estejam ocultas. Frente a esse contexto, portanto, há que buscar ampliar a compreensão do que está por trás das escolhas de professores e professoras quando se trata do uso de materiais midiáticos, dentre eles os filmes da boneca Barbie.

Há que desvelar a compreensão dose das docentes sobre o porquê dessas escolhas, tendo sempre presente nessa busca a perspectiva de que somos seres sexuados no mundo, educando-nos uns aos outros nas relações sociais sexuadas que estabelecemos no mundo, sendo, portanto, todas as pessoas, inclusive os profissionais da educação infantil, educadores e educadoras sexuais uns dos outros/as.

Essa necessidade dessa compreensão crítica brota do fato inegável de que mesmo essas aparentemente simples escolhas de filmes infantis contribuem, queiram ou não, saibam ou não esses e essas docentes, para os processos de educação sexual de suas crianças e mesmo dos seus, na maioria das vezes num processo de educação e formação continuada não intencional, sustentado por um currículo oculto que em muito contribui em processos de alienação das pessoas sobre a dimensão da sexualidade.

Neste sentido, buscar ouvir professoras de educação infantil considerando essa questão midiática que permeia seus cotidianos pessoais e profissionais, pode ajudá-las a ter momentos de reflexão crítica e consciente sobre a própria prática. Um dos objetivos da investigação que dá origem a essas nossas reflexões é, portanto, proporcionar às professoras um momento de reflexão sobre algumas de suas escolhas pedagógicas, para que elas, por sua vez, possam vivenciar com suas crianças, interações formativas mais qualificadas quando usam o apoio das várias linguagens midiáticas, buscando estimular a caminhada dessas docentes na direção de fortalecer a perspectiva de uma educação libertadora e nela, a de uma educação sexual emancipatória, apontada por Freire (2000, p.40):

A educação tem sentido porque o mundo não é necessariamente isto
ou aquilo, porque os seres humanos são tão projetos quanto podem ter
projetos para o mundo. A educação tem sentido porque mulheres e
homens aprenderam que é aprendendo que se fazem e se refazem,
porque mulheres e homens se puderam assumir como seres capazes de
saber, de saber que sabem, de saber que não sabem. De saber melhor o
que já sabem, de saber o que ainda não sabem.

Nessa perspectiva freiriana reafirmamos que há que se saber o que, na maioria das vezes, ainda não se sabe: o fato de que a educação sexual perpassa todas as pessoas 
e suas relações sociais no mundo todo, todo o tempo, inclusive nas comunidades escolares, onde crianças e professoras se educam também sexualmente. Reafirmamos que essa educação sexual muitas vezes não intencional, mas sempre presente, por mais que passe despercebida, é intensificada hoje pelas mídias e nela os filmes e, dentre eles, os da personagem Barbie.

Os desenhos, como os desses filmes, influenciam com muita força as crianças e são plenos de valores ideológicos. Muitos estudos já realizados apontam como as crianças os veem, mas agora é importante compreendermos como as professoras os compreendem, uma vez que muitos deles são utilizados nos diferentes espaços educativos nos quais as crianças circulam, tais como as escolas e seus próprios lares. É certo que nem todas as crianças os assistem diretamente, mas, mesmo para estas, os personagens e os enredos estão presentes em suas vidas via mercadorias/produtos oriundos da personagem e talvez tenha estado no passado dessas professoras, bem como estão com certeza no seu presente, via seus filhos e filhas, alunos e alunas, uma vez que a Barbie é uma personagem que atravessa já muitas décadas, personagem essa que é criação de um ser humano que nela põe as marcas de seu entendimento de mundo.

E isso tudo nos leva a refletir: será que há clareza das docentes sobre o que a personagem representa? As professoras compreendem o currículo oculto que permeia esses enredos? Professoras também são sujeitos históricos, como seus alunos, e juntos, eles tecem diversas e intensas trocas educativas no seu cotidiano. Como será então que essas professoras compreendem as influências dos filmes da boneca Barbie nos processos de educação sexual desses seus alunos?

Hoje é inegável que a boneca Barbie influencia inclusive o comportamento das crianças como consumidores, pois a personagem está estreitamente ligada ao surgimento da sociedade de consumo. Ela foi inserida dentro desse modelo de sociedade, numa realidade capitalista. Nesse sentido Sartori, Souza, Kamers (2011, p.4, grifo nosso) sinalizam que:

Há um conjunto de produtos comercializados a partir de personagens de desenhos animados e filmes infantis. Não raro, no caminho das escolas, vemos meninas e meninos usando mochilas, roupas e calçados que trazem estampas de vários personagens (Barbie, Power Rangers, Ben 10, Carros, Batman, Pequena Sereia, HotWheels, Homem Aranha, Minie, etc). 
Percebemos claramente que a personagem Barbie se desdobrou em muitos produtos, além da boneca em si. A personagem, em suas versões e mais, com o que é proposto pela sua aparência e as estórias/produtos que a cercam, forma e funde valores, cria tendências, torna-se forte mercadoria, o que envolve também e sempre, questões profundas relativas a dimensão da sexualidade, pelo papel de mulher que a boneca representa, e portanto, também o de homem, pelos estereótipos que difunde, etc..

Revendo a literatura sobre o tema, percebemos que já existem várias pesquisas relacionadas à personagem, muitas inclusive nas áreas da propaganda, design, moda, consumo etc., sendo que há várias pesquisas buscando desvelar motivações, crenças, atitudes ou sensações subjacentes em estudos que podem ser encontrados em artigos publicados na web, afirmando que a boneca Barbie influencia o comportamento do consumidor infantil. Entretanto uma análise voltada para a influência da personagem nos processos de educação sexual de crianças é ainda pouco explorada no Brasil.

Por todas essas questões o estudo proposto que subsidia esse texto busca desvelar a compreensão de professoras da educação infantil sobre as influências de filmes da Barbie em processos de educação sexual de crianças, ou seja, como compreendem a educação sexual ali subjacente, expressa nas falas, posturas, comportamentos, analisada a partir das vertentes pedagógicas brasileira de educação sexual cunhadas por Nunes (1996).

Entendemos ser necessário esse estudo pois pode fornecer indicadores de como propor a construção de propostas intencionais de educação sexual emancipatória com apoio de um uso crítico-reflexivo das tecnologias, dentre elas os filmes infantis, e nesses, os da Barbie.

É urgente e necessário estimular junto aos/as profissionais da educação a vivência de processos pedagógicos calcados no uso crítico das tecnologias e das suas várias ferramentas midiáticas, inclusive no que tange a dimensão da sexualidade que é, na maioria das vezes, reprimida num perverso currículo oculto mesmo na educação infantil. Nesse sentido, Melo, Teixeira e Pacheco (2012, p.197) já alertavam que:

Nos dias de hoje não há como negar a importância da utilização das diversas tecnologias como ferramentas pedagógicas, capazes de auxiliar no processo de ensino-aprendizagem, tornando assim as instituições escolares mais próximas dos estudantes, e possibilitando inclusive que a temática de sexualidade possa ser trabalhada intencionalmente com maior amplitude e motivação dos envolvidos, auxiliando na sensibilização e no debate sobre a dimensão humana da sexualidade. 
Entendemos ser a questão da educação sexual e suas interfaces com as mídias parte importante de um processo de sensibilização e debate sobre a dimensão humana da sexualidade. Nessa abordagem compartilhamos com Freire e Guimarães (2011, p.44) a ideia de que:

É evidente que a escola, enquanto instituição social e histórica, não pode cumprir sempre da mesma forma um certo papel que ela vem cumprindo, através do tempo e do espaço. Por outro lado, eu não diria que a escola tem de brigar com as novas presenças que se veem em torno dela. Presenças que vem surgindo em função do desenvolvimento da ciência e da tecnologia, e que, no campo da comunicação, as superam de longe

Ao mesmo tempo é preciso estar sempre atento, sobre o fato de que as tecnologias são fruto da ação humana, o que por sua vez as torna sempre plenas de intencionalidades. Alertam-nos ainda os autores acima citados sobre o fato de que:

[...] pensar em televisão ou na mídia em geral nos põe o problema da comunicação, processo impossível de ser neutro. $\mathrm{Na}$ verdade toda comunicação é comunicação de algo, feita de certa maneira, em favor ou na defesa, sutil ou explícita de alguma coisa contra algo ou contra alguém, nem sempre claramente referido. Daí também o papel apurado que joga a ideologia na comunicação, ocultando verdades, mas também a própria ideologização no processo comunicativo. (FREIRE; GUIMARÃES, 2011, p.236).

Neste movimento dialógico entre as crianças, professoras e as mensagens transmitidas pelas linguagens midiáticas, dentre elas os filmes da Barbie, a comunicação ocorre e é sempre "de algo, feita de certa maneira, em favor ou na defesa, sutil ou explícita de alguma coisa contra algo ou contra alguém, nem sempre claramente referido" (FREIRE; GUIMARÃES, 2011, p.236).

Hoje a massiva existência dos meios de comunicação e as diferentes linguagens midiáticas presentes no nosso cotidiano influenciam em muito a maneira dessa geração ver o mundo. Muitas vezes as crianças que recebem tais informações são muito pequenas, como é o caso da Educação Infantil e ainda incapazes de tecer por si mesmas relações críticas com esses meios, mas, mesmo assim, sempre interpretam e criam 
significados com as mensagens absorvidas, mesmo que isto não seja plenamente percebido pelos educadores e educadoras.

Coutinho e Quartiero (2008, p.11) enriquecem essa discussão ao afirmar que:

É fato o caráter ideologizador das mensagens da televisão e seu poder de sedução, que universaliza hábitos e cria no imaginário o ideal de uma sociedade nacional unida e democrática. Mas, as formulações teóricas que apontam a televisão como dominadora de espectadores passivos e acríticos, dirigida por donos que maquinam fórmulas de submissão plena da população, há muito são contestadas por teóricos, dentre eles Martin-Barbero (1987), que define o espectador como ator no processo de recepção, capaz de questionar as mensagens e contrapor-se às expectativas de emissores.

Dessa forma, cabe aqui ressaltar a importância de buscar estabelecer relações mediadoras críticas a serem vivenciadas pelos adultos nas suas práticas educativas com crianças quando apoiadas essas práticas com materiais oriundos de diversas mídias como se fossem neutros e não transmitissem valores. Não podem as crianças estarem "entregues aos meios midiáticos" sem espaços onde ocorram relações mediadoras críticas quase que imediatas, principalmente durante a prática pedagógica escolar onde ocorre, muitas vezes, o uso intencional pelas professoras de material como os filmes infantis, dentre eles também os da Barbie.

$\mathrm{O}$ educador e a educadora devem sempre estar atentos a esse entorno, mas também devem atentar para além dele e olhar criticamente do micro- o seu cotidiano, ao macro-a sociedade atual, retornando ao seu dia a dia. Para Paulo Freire (2006), o professor e a professora devem partir da realidade, problematizá-la e então buscar transformá-la. Freire fala em educação com uma intencionalidade, como ação política e afirma que a educação não é neutra. Para ele, a educação deve ser fundamentada em uma concepção de ser humano, sociedade, de conhecimento e de relação humanohumano - mundo.

Entendemos ser qualquer processo educativo sempre fundamentado nessas concepções, saibamos ou não disto. O que devemos fazer é qualificar essas concepções, numa abordagem emancipatória. Na medida em que os sujeitos mediatizados pelo mundo, conhecem e se comunicam sobre a realidade, o diálogo ganha sentido existencial e político, pois possibilita ao docente e ao aluno serem sujeitos não só de conhecimento, mas também da sua história e da sua cultura, tornando-os capazes de entenderem a sua realidade, para problematizá-la e modificá-la: 
Na educação, a mediação surge como possibilidade de levar adiante novas posturas voltadas à tolerância e ao respeito a diferentes visões de mundo dos envolvidos no processo de aprendizagem. O professor, como mediador de conflitos e emoções, incorpora uma prática na qual o diálogo, a escuta, o respeito às diferenças e às emoções indicam a possibilidade de inverter a lógica de uma prática "de transmissão de conhecimento e prescritiva" para outra construída na perspectiva da relação. Trata-se de uma mudança paradigmática para a educação: educadores aprendem ao mesmo tempo que os educandos. (ARRUDA, 2012, p.296)

Relembremos que, a partir da história expressa nos filmes da personagem Barbie, as crianças constroem cenários sociais e particulares no imaginário infantil, dando também vida a eles, com profundos significados para a existência humana, reforçando ou transformando paradigmas. E nesse contexto a dimensão da sexualidade está inclusa sempre, mesmo que não percebida, já que é inseparável do existir humano.

Como apontou Nunes (1997, p. 16) "a sexualidade é, de maneira privilegiada, o terreno híbrido entre o pessoal e o social, encruzilhada confusa onde se articulam o ser e o existir individual de cada um de nós".

Isso pode ser relacionado ao estudo da personagem Barbie em seus filmes (BARBIE..., 2011), por exemplo, quando suas atitudes levam especialmente crianças do sexo feminino que a assistem a um processo de imaginação e de busca de transformação das meninas, no caso, de transformação em "princesas", que é o destaque dos filmes que serão utilizados nessa investigação. Isso porque é fato conhecido que a Barbie muito aparece nas atitudes das crianças que tanto buscam imitá-la tornando-se "lindas princesas", como também vivenciam valores ao colocar a boneca em situações que elas já percebem ao seu redor. Nesse exercício de buscar um modelo de vida para meninas colocam a boneca para fazer o que elas gostam, ou são ensinadas pela personagem a gostar, como ir ao shopping, fazer algum esporte, namorar etc.. Criam as crianças, majoritariamente as meninas, estórias envolvendo família, namorados, amigas da boneca, pois a Barbie pode estar casada, com filhos, ou solteira, indo ao restaurante com seu namorado, sendo que na estorinha infantil, eles brigam, fazem as pazes etc. todas essas ações permeadas de definições pré estabelecidas de maneiras de ser e estar hoje no mundo como meninas e meninos, enfim como mulheres e homens.

Essas estórias refletem o poder dessa mídia e do estímulo ao consumismo, pois para crianças, e muitas adultas e adultos, dentre elas talvez muitas das professoras, a 
Barbie é um modelo perfeito da mulher moderna, inclusive em seu modelo de corpo "perfeito", representando aquilo que muitas meninas e mulheres adultas gostariam de ser, e que muitos homens esperam que sejam.

Mas há que relembrar que Kenski (2009, p.17) chama nossa atenção para as evidências de que:

Os vínculos entre conhecimento poder e tecnologia estão presentes em todas as épocas e em todos os tipos de relação social. Enciclopédias, dicionários, livros, revistas e jornais, por exemplo, são criados em contextos definidos e apresentam informações sobre a ótica de seus autores e editores, ou seja, a informação veiculada em jornal, revista ou livro não envolve a totalidade de informações sobre determinado assunto nem pode ser considerada totalmente isenta e imparcial.

Relembremos que filmes infantis também são linguagens midiáticas importantes que apresentam informações sobre a ótica de seus autores, que produzem cultura, educam, intencionalmente ou não, claramente ou subliminarmente, trazendo informações, imagens, representações, e estão presentes nas escolas, não podendo ser considerados nunca como isentos e imparciais.

Hoje essas diferentes linguagens causam muita influência sobre o processo de ensino-aprendizagem, uma vez que a maioria das práticas pedagógicas vividas pressupõem e usam apoio de exemplos da vida cotidiana onde a literatura, o cinema, a música e as demais artes, com seus inúmeros personagens, estão constantemente presentes, delineando modelos dessa vida cotidiana, muitas vezes sem que os usuários dessas ferramentas midiáticas reflitam sobre quem definiu e o porquê esses modelos. Reafirmamos nossa questão central: como as professoras de educação infantil compreendem esse processo?

Nessa direção reflexiva buscar compreender as interfaces entre educação e sexualidade, a partir de filmes da personagem Barbie, meio midiático cada vez mais poderoso, pode propiciar espaço para as professoras vivenciarem uma reflexão crítica urgente e necessária sobre os paradigmas e as vertentes pedagógicas que estão embasando a maneira como as crianças vivenciam a sua sexualidade, ou seja, como vivenciam um processo diário de educação sexual, inclusive nas salas de aula da educação infantil.

Processos intencionais de educação sexual, numa perspectiva de emancipação do ser humano, podem em muito ser potencializados com o uso crítico de materiais já 
existentes, bem como com a produção pedagógica de materiais que expressem conteúdos na direção de sensibilização para a temática da dimensão da sexualidade, entendida como parte indissociável da vida humana.

Para tanto é preciso repensar esses fenômenos, dentre eles, refletir sobre a possibilidade de uso crítico de filmes da boneca Barbie, frutos que são esses filmes de seres humanos, e, portanto, plenos de intencionalidade, pois reafirmamos que esses filmes muito influenciam hoje os processos educativos destas crianças que estão indo hoje para a escola na educação infantil. Dessa forma se faz necessário pensar esses fenômenos de modo crítico sistemático buscando desvelar a compreensão de professoras da educação infantil sobre esse tema, por entendê-las em permanente vir a ser, capazes de se constituírem profissionais cada vez mais preparadas para um uso crítico das tecnologias, questionando e avaliando cada uma dessas ferramentas midiáticas, percebendo o conhecimento que brota nelas, mas gerando novos conhecimentos críticos a partir delas, entendendo-as reflexivamente no seu existir junto ao contexto dessas crianças que vivem cotidianamente permeadas por essas linguagens desses novos tempos.

Portanto, devido ao alcance que a personagem Barbie exerce há tanto tempo, em tantas pessoas, em todo o mundo, entendemos ser importante analisar a compreensão de professoras da educação infantil sobre as influências de filmes dessa boneca, especialmente os que buscam tornar cada menina em uma princesa, em um processo de educação sexual alienante de nossas crianças.

Há que atentar especialmente para a questão da construção das maneiras dessas crianças constituírem-se como pessoas sexuadas, pois pode a investigação levantar indicadores de categorias fundamentais presentes na compreensão dessas professoras a partir desses filmes, e que possam ajudá-las no desvelamento de que, na maioria das vezes, estão subsidiando um currículo oculto, reificador de maneiras repressoras de viver, especialmente para as mulheres, e por consequência, para os homens, refletindose, portanto em todo o espaço social contemporâneo.

\section{BARBIE MOVIES INFLUENCE ON SEX EDUCATION OF CHILDREN: SEARCHING THE UNDERSTANDING OF THE TEACHERS ABOUT THE THEME}


ABSTRACT: This article aims to reflect on the importance of unveil the understanding of teachers about the influence of the Barbie's movies in sexual education of children. We understand that we are all sexual beings in educational relationships with each other and with the world, these relationships that build knowledge always sexed. Since we are sexual beings, therefore we weave social relations that are also relations of sex education, with or without intent. These educational relationships today are permeated by the intense use of various technological tools that are expressed in many kinds of media's language, and are never neutral in its contents. Among these languages children's films are often used as support for formal and non-formal educational processes and influence the child's imagination. Among the children's films, the character of Barbie is commonly used in the selection of teachers as pedagogical object inside many classrooms as part of everyday life. The unveiling of how educators understand the consequences of these films in the sexual education of their students may point to new possibilities for critical and pedagogical use of these movies.

KEYWORDS: Emancipatory Sex Education. Barbie movies. Sexuality. Media.

\section{REFERENCIAS}

ARRUDA, M. P. O paradigma emergente da educação: o professor como mediador de emoções. Educação Temática Digital, Campinas, v.14, n.2, 2012. Disponível em: <http://www.fae.unicamp.br/revista/index.php/etd/article/view/2935/pdf >. Acesso em: 25 fev. 2015.

BARBIE: Escola de Princesas. Direção: Zeke Norton. Produção: Shawn McCorkindale e Shelley Tabbut. Roteiro: Elise Allen. Estados Unidos: Universal, 2011. 1 DVD (79min), son., color.

CARVALHO, G. M. D. "Tá ligado!?": diálogo entre adolescentes e telenovelas da rede Globo: interfaces na construção da compreensão da sexualidade. 2009. 174 p. Dissertação (Mestrado) - Universidade do Estado de Santa Catarina, Centro de Ciências Humanas e da Educação, Mestrado em Educação, Florianópolis, 2009.

COUTINHO, L. M.; QUARTIERO, E. M. O Merchandising Social na Telenovela Malhação: estratégias sócio-educativas para adolescentes. In: SEMINÁRIO DE PESQUISA EM EDUCAÇÃO DA REGIÃO SUL, 7., 2008, Itajaí, SC. Anais... Itajaí, SC: ANPEdSUL: UNIVALE, 2008. v.1. p.1-15.

FREIRE, P. Extensão ou Comunicação?. 13.ed. São Paulo: Paz e Terra, 2006.

Pedagogia da indignação: cartas pedagógicas e outros escritos. São Paulo: Ed. da UNESP, 2000.

FREIRE, P.; GUIMARÃES, S. Educar com a mídia: novos diálogos sobre educação. São Paulo: Paz e Terra, 2011. 
KENSKI, V. M. Educação e tecnologias: o novo ritmo da informação. 5.ed. Campinas: Papirus, 2009.

MELO, S. M. M. de; TEIXEIRA, M. dos S.; PACHECO, R. da V. Reflexões sobre a caminhada de produção do programa de TV "Educação Sexual em Debate" como material pedagógico de apoio a processos de educação sexual emancipatória. In: SOUZA, C. B. G.; RIBEIRO, P. R. M. (Org.). Políticas Públicas em Educação no Contexto Ibero-Americano. São Paulo: Cultura Acadêmica, 2012.

NUNES, C. A. Desvendando a sexualidade. Campinas: Papirus, 1997.

Filosofia, sexualidade e educação: as relações entre os pressupostos éticosociais e histórico-culturais presentes nas abordagens institucionais sobre a educação sexual escolar. 1996. 319f. Tese (Doutorado em Educação) - Faculdade de Educação, Universidade Estadual de Campinas, Campinas, 1996.

SARTORI, A. S.; SOUZA, K. R.; KAMERS, N. J. Desenho Animado, Tv e YouTube: Reflexões Sobre Educomunicação e Linguagens. In: Congresso Brasileiro de Ciências da Comunicação, 33., 2011, Recife. Anais... Recife: Intercom, 2011. Disponível em: <http://www.intercom.org.br/papers/nacionais/2011/resumos/R6-0788-1.pdf>. Acesso em: 25 fev. 2015.

SOARES, I. O. Mas, afinal, o que é educomunicação?. Disponível em: <http://www.usp.br/nce/wcp/arq/textos/27.pdf>. Acesso em: 15 fev. 2015. 